\title{
Sciendo
}

DOI: $10.2478 / \mathrm{aa}-2019-0010$

\section{Doctor Who meets Loving Vincent Van Gogh (A case study of the "tortured artist" stock character in popular culture)}

Martin Boszorád

Martin Boszorád (1985) received his $\mathrm{PhD}$ in the field of aesthetics after earlier studies in aesthetic education and German language and literature. He is currently the head of the Institute of Literary and Artistic Communication (Constantine the Philosopher University in Nitra, Slovakia). His research interests include mainly the theorization of popular culture. He has coauthored two monographs and five textbooks and has written more than 20 scientific papers published in diverse journals and collective volumes and around five dozen literary or film reviews and articles devoted to the topic of (pop)culture.

Abstract: Methodologically connecting at its core the experience-based and interpretationbased aesthetic approach to popular culture/popular art(s) on one hand and the basis-building views of what is called arch-textual thematology on the other, the paper seeks to examine, following its particular embodiment, one of the most stable, recurring and probably therefore one of the most iconic stock characters - the "tortured artist" stock character. This example of a "stereotyped character easily recognized by readers or audiences from recurrent appearances in literary or folk tradition" (Baldick, 2008, p. 317) can be - besides other principal and distinctive examples such as the "mad scientist", the "lady/damsel in distress" or, let's say, the "everyman" - witnessed all across culture, including the sub-sphere of popular culture, and the arts. The implied cultural significance and "omnipresence" of the "tortured artist" stock character can be aptly illustrated by Vincent Van Gogh and not only as a real-life tortured artist prototype or even archetype but also as a popular model for numerous and various cultural depictions - from poems by Charles Bukowski through the "moving pictures" of Loving Vincent to an episode of the well-recognized British TV show Doctor Who.

"What am I in the eyes of most people? A nonentity or an oddity or a disagreeable person - someone who has and will have no position in society, in short a little lower than the lowest./ Very well - assuming that everything is indeed like that, then through my work I'd like to show what there is in the heart of such an oddity, such a nobody./This is my ambition, which is based less on resentment than on love in spite of everything, based more on a feeling of serenity than on passion./

Even though I'm often in a mess, inside me there's still a calm, pure harmony 
and music [emphasis added]. In the poorest little house, in the filthiest corner, I see paintings or drawings. And my mind turns in that direction as if with an irresistible urge." (Vincent Van Gogh in one of his letters to his brother Theo) ${ }^{1}$

"Van Gogh cut off his ear/gave it to a/prostitutel who flung it away in/extreme/disgust./ Van/whores don't want/ears/they want/money. /I guess that's why you were/such a great/painter: you/didn't understand/much/else [emphasis added]." (Charles Bukowski: Working Out $)^{2}$

In the arts - and the arts in the widest possible sense, i.e. from literature as a classical art form through comics as a transitional one to tattoo art as a fringe-based but increasingly acknowledged art form - several pivotal appearances of autothematism, of art thematizing and following itself in some way, can be noticed. In this way literary works of art depict the story of how literary works of art come into existence (e. g. Stephen King's novel Misery) or how they are being read (e.g. Italo Calvino's novel If on a Winter's Night a Traveller); superhero comics redefine and reconceptualize their determinative and earlier conventionalized character - the superhero (e.g. Alan Moore's and Dave Gibbons's Watchmen); and neo-traditional tattoos, as the appellation per se anticipates, not only appreciatively revisit (outlining) but also in a revolutionary manner update (inspired by Art Nouveau) the classic, traditional style of tattooing.

Within this context, the character of an artist featured in an oeuvre can be understood as the epitome of one appearance of the self-referentiality of art, either an "inner" (e. g. literature thematizing literature) or an "interlinking" one (literature thematizing for example fine arts or cinema). What we, more precisely, have in mind here is that form of self-referentiality which unfolds around the character of an artist in such a manner as within the novel type of the wellestablished Künstlerroman (artist-novel; e.g. J.W. Goethe's Wilhelm Meister's Apprenticeship, James Joyce's A Portrait of the Artist as a Young Man and John Irving's The World According to Garp) roots which spatially stretch out to Germany and in terms of time at least to the turn of the $19^{\text {th }}$ century. 
The presence of artist-characters seems to be, when observing the past as well as the present of the art-sphere, an integral part of literary output and even artistic production in general. Therefore it probably comes as no surprise that when the authors of the thematological handbook entitled Themen und Motive in der Literatur (1995; first German edition: 1987) reflect on the basic, founding building stones of literary works of art, they incorporate into the list of lexicon-entries also the headword "Künstler" (artist). Within the frame of this, Horst S. Daemmrich and Ingrid D. Daemmrich (1995, p. 231) initially connect the increasing significance of the artist-character as a thematic element with the works of the German homo universalis J. W. Goethe, subsequently accentuating that the topic has since then been established - and extensively thanks to Goethe's literary output - as considerably internally nuanced and in terms of its factual appearances polymorphous. Furthermore, the authors mention in this connection issues such as the individual-psychological aspects of the personality of an artist, the talent-related circumstances (mission, inspiration, curse, madness) or the relationship between the artist and society, the process of creation and/or his work as such etc.

In works of art the portrayal of tensions or the discord between the textual representation of an artist and society is especially worthy of attention. The authors of the book Themen und Motive in der Literatur affirm this unequivocally by arguing that "depictions of artist-characters which aren't able to harmonize their view upon life with notions of society are of great importance" (Daemmrich - Daemmrich, 1995, pp. 231-232; translated from German by M. B.). In narratives constructed around this thematic element, artist-characters are forced to face a defiance that leads to escapist tendencies, literal as well as figurative, states of despair and torment frequently resulting in a, when we appropriate the terms related to the unified structure of Greek tragedy, catastrophic climax - madness $^{3}$ or even suicide (Daemmrich - Daemmrich, 1995, pp. 231-232). And exactly this tension unfolded around artist-characters as extraordinarily sensitive and perspicacious entities seeing the world differently, ${ }^{4}$ even seeing, poetically speaking, behind the notional veil of Maya, who barely can meet the requirements laid out for them by society, can be understood as the very basis of why what's denoted by the collocation "tortured artist" has acquired the status of a stock character (in art) and a proverbial stereotype and even a cultural or cultural-civilizational meme (in real life). ${ }^{5}$

A noteworthy and in connection with the tortured-artist phenomenon inspiring, albeit rather popularizing than academic, survey of the tortured-artist-topic is offered in his book entitled Tortured Artists. From Picasso and Monroe to Warhol and Winehouse, the Twisted Secrets of the World's Most Creative Minds (2012) by the New York-based writer, critic and journalist Christopher Zara. 
As the book's title foreshadows, Zara focuses in his reflection on real-life tortured artists, not their representation in art per se; however, some circumstances defining his approach to the tortured-artist phenomenon by all means deserve attention. Although the very first sentence in the book's introduction "[i]t is sometimes said that all great art comes from pain" (Zara, 2012, p. 7) could be perceived as a little too simplifying, the subsequent explication definitely seems plausible, as the author also attempts to follow up pain and torment in (art) history:

The connection between pain and art - i.e., the tortured-artist phenomenon - is probably as old as art itself. Admittedly, we have no evidence of cave painters drowning their sorrows in absinthe at trendy cafés around Paleolithic Europe, but we do know that, even then, art represented some of the most enduring hardships of society. Prehistoric paintings often depicted violent scenes of Cro-Magnon hunters being trampled by wounded animals. They were ancient obituaries, and they offer a telling window into the roots of art itself showing pain and suffering as elementary components of creative process. One of the earliest acknowledgments of the link between creativity and mental distress appears in Plato's Phaedrus ${ }^{6}$, a dialogue in which Socrates asserts that Muses themselves must inflict Greek poets with a 'divine madness'. Centuries later, Shakespeare likened his own literary vocation to insanity. 'The lunatic, the lover and the poet / Are of imagination all compact,' he wrote in Midsummer Night's Dream. (Zara, 2012, p. 10)

Zara unquestionably makes the topic in terms of reading accessible, nevertheless, what prima facie may sound banal or superficial conceals valid as well as valuable insights concerning the art-pain-life ${ }^{7}$ interconnection:

Everything humans do is the product of struggle. We invented clothes because we were cold. We build houses because we were getting rained on. We created laws because we were killing each other. You might ask why art should be any different. It's different because, even though we invented clothes, houses, and laws, we still get cold, we still get rained on, and we still kill each other. Art brings meaning to all that. It puts our pain in perspective. (Zara, 2012, p. 12) 
Zara uncovers a lot when reflecting on the kaleidoscopic image of the tortured-artist topic, whereby some of his crucial observations are actually immaterial, more implicit, "hidden" for example in the composition of his book. ${ }^{8}$ Zara's approach to the topic and systemization of tortured artists indeed is diachronic, but rather in a "metonymic" rather than chronological manner, as he ties particular tortured artists following an interior link between them - the very nature of their torment. And thus for instance in chapter 3 entitled Perpetual Virginity. Unrequited Love and the Tortured Artist (or, Your Muse Is Just Not That Into You) Dante Alighieri "encounters" Charles M. Schultz, or in chapter 5 entitled Rage Against the Machine. How I learned to Stop Worrying and Blame Society Edgar Alan Poe "meets" Chuck Berry. The author "upholds" this perspective also in the last albeit in connection with the topic in a way starting-point-related chapter of the first part of his book - Archetypes. Touchstones of the Touched - by putting together Marilyn Monroe, Sylvia Plath, Kurt Cobain and Vincent Van Gogh:9 "Four people - an actress, a writer, a musician, a painter - have not only lived up to tortured-artist folklore but helped define it" (Zara, 2012, p. 206).

As Vincent Van Gogh or, to be more precise, his representation as an archetypal, modellike epitome of the "tortured artist" stock character, ${ }^{10}$ is what we are concerned with in this paper, what Christopher Zara states, when introducing his archetypes-chapter, is for sure worth mentioning:

The aim is to show how the archetype of the tortured artist played out in the lives of these four troubled souls, each of whom took the gamble of choosing art over safety. Marilyn left behind a perfectly safe marriage to seek out Hollywood. Sylvia exposed her worst enemies in a thinly veiled novel. Kurt ditched underground success for a chance to change the direction of mainstream music. Vincent traded any semblance of security to live in poverty as a painter. In these instances, all four of these figures showed that they were willing to risk everything for their art. Can there be a truer definition of an artist? (Zara, 2012, p. 206)

Vincent Van Gogh has beyond doubt acquired not only the status of a model-like real-life tortured artist but also of a cultural icon, at least to the extent of the definition of a cultural icon elaborated by Danish scholars Bent Sørensen and Helle Thorsøe Nielsen (2015, p. 7): “A commercialized, yet sacralized visual, aural or textual representation anchored in a specific temporal/historical and spatial/geographical context, broadly recognized by its recipients as having iconic status for a group of human agents within one or several discursive 
fields/communities." After all, there really are not many artists whose interiorly polymorphous yet reciprocally consistent representations are more commercialized than those of Vincent Van Gogh. And although it may seem absurd, his broadly, probably even globally, recognized representation in toto evinces regardless of what may be a priori understood as categorical profanation a high grade of canonization. Van Gogh, as our empirical experience of the world affirms, indeed is strongly commodified (there is, for instance, a lot of various Van-Goghmerchandise in circulation), nevertheless, his textual and/or audio-visual representations as a rule are respectful, appreciatory and adoring. The animated biographical drama Loving Vincent (2017), as well as the episode of the British TV show Doctor Who ${ }^{11}$ entitled Vincent and the Doctor (2010) can be certainly understood as eloquent evidence of the aforementioned.

When Bohumil Fořt discusses narratological aspects of literary characters, he repeatedly points out (2008, p. 97) that there's a substantial difference between characters featured in fictional narratives and their potential counterparts in the actual world in terms of the nature of their existence as characters are pure mental constructions fundamentally defined by incompleteness because they are embedded in finite stories. Although this thesis barely can be called into question - even if the borders of literature are crossed - the case of Vincent Van Gogh's representations, at least those iconic ones, proves that despite being constructed and at the same time incomplete in their very core they, so to speak, stick to the model or rather template and its cultural resonance. Moreover, they do it - hence the title of the "world's first fully painted feature film" - with love.

For that reason, when Dorota Kobiela, the writer and director of Loving Vincent, was asked to clarify the film's title, she answered the question as follows:

This project has been a labour of love. I've worked on it a total of 7 years full time, my love of Vincent's work, his letters and my respect for his struggle sustained me for those 7 years. And it wasn't just me that had to love Vincent. Our team of painters were painstakingly painting 65,000 frames of oil painting, spending up to 10 days painting a second of film, moving each brush-stroke frame by frame. That takes a lot of commitment, a lot of respect for his work. Thirdly it is a reference to how he often signs off his letters to his brother 'Your loving Vincent'. And perhaps most importantly we only decided to take the risk of making the world's first fully painted feature because of how much people around the world are already loving Vincent. I hope this film will inspire people to find out more about Vincent, read his letters, see his paintings in the flesh. I hope I will have, in some small way, 
helped introduce Vincent to more people. I think he deserved that. I want everyone to be loving Vincent! (“Loving Vincent Press Kit”, lovingvincent.com)

Interestingly, aside from the title per se also the initial "ideological" background of the film project is in accordance with what was already stated regarding the stock-like nature of Van Gogh's massive cultural "echo":

As remarkable as Vincent's brilliant paintings, is his passionate and ill-fated life, and mysterious death. No other artist has attracted more legends than Vincent Van Gogh. Variously labelled a martyr, a lustful satyr, a madman, a genius and a layabout, the real Vincent is at once revealed in his letters, and obscured by myth and time. Vincent himself said in his last letter: 'We cannot speak other than by our paintings'. We take him at his word and let the paintings tell the real story of Vincent Van Gogh (“Loving Vincent Press Kit”, lovingvicent.com).

When again referring to Fořt's considerations, this time those in which he (2008, p. 76) reverts to the dichotomy of the character-definitions and character-hypotheses elaborated by Daniela Hodrová, the representation of Van Gogh as a real-life model, albeit what we are concerned with in this case is not a literary character, in Loving Vincent seems to be, so to speak, caught up in-between. On one hand the depiction corresponds not merely contour-wise with its model (after all, following the above cited words, the aim was to tell the real story), therefore it can be perceived as defined, which implies explicit and fully determined; on the other hand it is to some extent enigmatic, ergo (hence Hodrová's concept) hypothetical. One could argue that being enigmatic is in this context being in correspondence with the model as such, however, the in-betweenness of Van Gogh's representation is conceived and, in fact, even amplified by the way how Van Gogh's character is (non)present in the narrative, as the plot of the film is set one year after his death and he thus appears only within the frame of black-and-white flashbacks.

There could be some dispute over why and how Loving Vincent as an experimental biopic even art film can be reflected within the frame of popular culture. The first argument is that there conclusively exist many films, e.g. films directed by Jim Jarmusch, which precedentially obliterate the line between art films and films that can be understood as pertaining to popular culture. Moreover, in the case of Loving Vincent in particular there are no less than two more arguments - one being in connection with the film interior and one being 
exterior. As the contentual facet has unequivocally determined the film's formal facet (it was hand-painted, whereby the film stuck to Van Gogh's actual works of art and the utilized filmpainting technique stuck to Van Gogh's unique style), so does the contentual facet enable one to perceive the film as a popular culture artefact. It is, after all, a film thematizing the life and work of one of the most popular artists of all time. Concerning the latter argument, the extrafilmic one, in 2017 Loving Vincent, praised by audiences, won the "Most Popular International Feature" at the Vancouver International Film Festival, not to mention that, at least according to the film's website, it also gained the status of a box office hit.

In comparison with Loving Vincent, there is absolutely no room for doubt when the cultural status of the TV series Doctor Who is under consideration. Doctor Who is an integral part of popular culture, even an emblematic and therefore core-like one. Since its original release in the 1960s the TV show has earned the rank of cult status in popular culture as well as the title of the longest-running science fiction series, evincing high impact and remaining "a particular object of public and TV sci-fi fandom affection ${ }^{12}$ " (Lewis \& Stempel, 1993, p. 18). As Jon E. Lewis and Penny Stempel (1993, p. 18) furthermore point out in their essential critical guide entitled Cult TV, Doctor Who was originally conceived as a children's education programme, whereby it was intended "to be a means of explaining past ages and the physical sciences" (Lewis \& Stempel, 1993, p. 18). ${ }^{1}$ Albeit the nature of the show has changed within the frame of more than five decades, at intervals Doctor Who returns, so to speak, to its roots by travelling back - at least partially - along mankind's timeline and re-visiting history. And thus the titular character and the viewers with him could in the revived era $^{13}$ of the series meet besides Charles Dickens (The Unquiet Dead, 2005), William Shakespeare (The Shakespeare Code, 2007) or Agatha Christie (The Unicorn and the Wasp, 2008) also Vincent Van Gogh as, in fact, the first non-British artist-figure featured in the show.

The leitmotiv of the episode, featuring Van Gogh's representation, entitled Vincent and the Doctor is in concordance with the aforementioned general approach to artist-characters depicted in works of art as those who see more than others, who see the world differently - in this case both in a figurative and literal sense, whereby the literal sense per se drives the narrative practically right from the start. When visiting The Museé d'Orsay the Doctor and his companion Amy Pond notice that one of Van Gogh's most iconic paintings (The Church at Auvers) features a strange element - a "face of evil", as Doctor comments on it: "I know evil when I see it and I see it in that window". As it later turns out, what Van Gogh was able to 
portray, as the only person who could see it, was a Krafayis, an invisible extra-terrestrial creature which was, being blind, utterly abandoned by its species and left to solitarily rove in the dark until death.

In addition, there are at least two more sequences in the episode's story, within which Van Gogh's ability to perceive more, or differently, is directly thematized or illustrated, in both cases in direct connection with his art. In one particular dialogue with the Doctor, Van Gogh's character states: "You know, it seems to me there's so much more to the world than the average eye's allowed to see. I believe, if you look hard, there are more wonders in this universe than you could ever have dreamed of. [...] It's colour! Colour that holds the key! I can hear the colours. Listen to them. Every time I step outside I feel nature is shouting at me." Consequently the leitmotiv culminates when the three main characters are looking at the night sky and Van Gogh pronounces the following words:

Try to see what I see. We're so lucky we're still alive to see this beautiful world. Look at the sky. It's not dark and black and without character. The black is in fact deep blue. And over there! Lights are blue. And blue in through the blueness, and the blackness, the winds swirling through the air... and then shining. Burning, bursting through! The stars, can you see how they roll their light? Everywhere we look, complex magic of nature blazes before our eyes.

In this moment the night sky changes its appearance as if painted in a Van Gogh-style, and thus the Doctor and Amy Pond along with the audience are finally able to see the world Van Gogh-like ${ }^{14}$ what the Doctor comments as follows: "I've seen many things, my friend. But you're right. Nothing's quite as wonderful as the things you see."

What is within the frame of the episode, naturally, almost as vehemently conveyed as Van Gogh's extraordinary perspicacity and ability of perception (hence the torturedartist topic of the artist-part) are his "demons" (hence the tortured-artist topic the torturepart). Thus Van Gogh's character can be seen as unsatisfied with his work, feeling fatal solitude and hopelessness, tormented by his melancholy and rapid change of moods and life-attitudes - all this effectively uncovers his very fragility.

Albeit containing also humour and some sensitively incorporated moments of pure amusement, in its core the episode definitely appears to be dramatic. This undoubtedly affirms also its composition. Regarding its structure, Vincent and the Doctor basically has two major climax-points in which the two sides of one notional coin - of Vincent Van 
Gogh being an epitome of the tortured-artist subject-matter, i.e. an artist and simultaneously a troubled individual - come to expression. The first climax-point is played out when Van Gogh's character, within the frame of rewriting time and history taken by the Doctor into the future and to The Musée d'Orsay, gets to know his actual cultural impact as an artist. Subsequently, the second climax-point of the story eventually exposes the fact that Van Gogh's "demons" were, even despite him knowing the future, simply stronger.

Interestingly, the first climax-point, so to speak, the - for Van Gogh's character as well as for the audience cathartic - pre-finale is probably more significant than the factual ending of the episode. When the Doctor asks the museum curator to evaluate Van Gogh in art history, while the artist is non-declaratively listening, he gets the following answer:

Well, hm, big question, hm, but to me, Van Gogh is the finest painter of them all. Certainly the most popular great painter of all time. The most beloved. His command of colour, the most magnificent. He transformed the pain of his tormented life into ecstatic beauty [emphasis added]. Pain is easy to portray but to use your passion and pain to portray the ecstasy and joy and magnificence of our world. No one had ever done it before. Perhaps no one ever will again. To my mind, that strange wild man who roamed the fields of Provence, was not only the world's greatest artist but also one of the greatest men who ever lived.

In conclusion, when referring back to the aforementioned insights of Christopher Zara regarding the tortured-artist phenomenon, it seems as if not only art puts pain into perspective, but also, vice versa, pain puts art into perspective. This is at least valid in the case of Vincent Van Gogh as the probably most significant, template-building, and simultaneously, naturally, within the frame of art and (popular) culture most referenced and (re)presented tortured artist ever.

\section{Works cited:}

Baldick, C. 2008. The Oxford Dictionary of Literary Terms. Oxford: Oxford University Press. Cook, J.R. - Wright, P. (eds.). 2006. British science fiction television. A hitchhiker's guide. London/New York: I. B. Tauris. 
Čechová, M. 2017. “Arcitextuálna tematólogia” In: Litikon - časopis pre výskum literatúry, Vol. 2, No. 1, pp. 280-282.

Daemmrich, H. S. - Daemmrich, I. D. 1995. Themen und Motive in der Literatur. Ein Handbuch. Tübingen/Basel: Francke Verlag.

Fořt, B. 2008. Literární postava. Vývoj a aspekty naratologických zkoumání. Praha: Ústav pro českou literature AV ČR.

Hills, M. 2010. Triumph of a Time Lord. Regenerating Doctor Who in the twenty-first century. London/New York: I. B. Tauris.

Homburg, C. "The Insane Artist or Genius at his Best. Vincent Van Gogh, a Case in Point?" In: semanticscholar.org [qt. 2019-08-29], pp. 77-88. Available at: $<$ https://pdfs.semanticscholar.org/2544/79274fa68341aaafcdf278edf9657258c84b.pdf $>$.

Jansen, L. - Luijten, H. - Bakker, N. 2009. “The letters.“ In: Vangoghletters.org [qt. 2019-0829]. Available at: $<$ http://Vangoghletters.org/vg/letters.html $>$.

Lewis, C. - Smithka, P. (eds.) 2010. Doctor Who and Philosophy. Bigger on the Inside. Chicago/La Salle: Open Court.

Lewis, J. L. - Stempel, P. 1993. Cult TV. The Essential Critical Guide. London: Pavilion Books Ltd.

“Loving Vincent Press Kit.” In: lovingvincent.com [qt. 2019-08-29], pp. 1-34. Available at: $<$ http://lovingvincent.com/images/glowne/Loving\%20Vincent $\% 20 \% 20$ Press $\% 20$ Kit $\% 20$ US.p df $>$.

Wallace, R. 1972. The World of Van Gogh: 1853 - 1890. New York: Time-Life Books, 1972. "Working Out.” In: bukowski.net [qt. 2019-08-29]. Available at:

$<$ https://bukowski.net/database/detail.php?w=3999\&Title=working-out $>$.

Shusterman, R. 2000. Pragmatist Aesthetics. Living Beauty, Rethinking Art. Lanham: Rowman \& Littlefield Publishers.

Sørensen, B. - Nielsen, H. Th. 2015. "Cultural iconicity. An emergent field.“ In: Akademisk kvarter/Academic Quarter, Vol. 10, pp. 5-20. Available at:

$<$ http://www.akademiskkvarter.hum.aau.dk/pdf/vol10/Introduction_BentSoerensen_HelleTNi elsen.pdf $>$.

Stone, I. 2018. Lust for Life. London: Cornerstone.

Sussman, A. 2007. "Mental Illness and Creativity: A Neurological View of the 'Tortured Artist'." In Stanford Journal of Neuroscience, Vol. 1, No. 1, pp. 21-24.

Tulloch, J. - Jenkins, H. 1995. Science fiction audiences. Watching Doctor Who and Star Trek. London and New York: Routledge. 
Zara, C. 2012. Tortured artists. From Picasso and Monroe to Warhol and Winehouse, the Twisted Secrets of the World's Most Creative Minds. Avon: Adams Media.

\section{Endnotes}

${ }^{1}$ See more and compare the letter written by Van Gogh on or about Friday, 21. July 1882: http://Vangoghletters.org/vg/letters/let249/letter.html. Even prima facie, words like "suffering", "torture" or "torment" seem to frequently recur in the artist's correspondence. As Christopher Zara (2012, p. 222) puts it, "[c]ollectively, the letters were a quasi-memoir of personal decline, weaving together a heartbreaking narrative of creativity, madness, and the relationship between the two".

${ }^{2}$ For Bukowski as the "lowlife" enfant terrible of American literature Van Gogh was apparently pretty inspirational. Poems Van Gogh and 9 innings and Beasts Bounding Through Time can be, besides Working Out, understood as eloquent evidence of that. For more information about Bukowski's works see https://bukowski.net/.

${ }^{3}$ Concerning madness as a recurring basic/founding thematic element of literary works of art see the entry "Wahnsinn" in the handbook Themen und Motive in der Literatur; Daemmrich - Daemmrich, 1995, pp. 368-372.

${ }^{4}$ According to Adrienne Sussman, “...drawing unusual connections or thinking in a unique way are hallmarks of the artistic mind" (Sussman, 2007, p. 22).

${ }^{5}$ As A. Sussman (2007, p. 21) puts it, [t] he contradiction of the genius who creates great artwork despite (or because of) mental illness has been part of Western legend for thousands of years".

${ }^{6}$ Also A. Sussman (2007, p. 21) and C. Homburg (p. 78) articulate the connection between the "mad genius/artist" and Plato's dialogues (Phaedrus, Ion). Moreover, both authors, unlike Zara, accentuate while inquiring into the history of the stereotype, the large influence of Romanticism.

${ }^{7}$ Because following the theme in the context of a "founding experience-related wisdom which is above-individually, historically and also praxeologically verified" (Čechová, 2017, pp. 280; translated from Slovak by M. B.) and fundamental existential strategies, feelings or experience, that means in a simplified way - in the context of life, arch-textual thematology, as defined by Mariana Čechová (2017, pp. 280-282), is a valuable methodological source also when reflecting the "tortured artist" stock character and its occurrence in (popular) culture.

${ }^{8}$ Zara's book is considerably illogically and not proportionally divided into two parts: Part I: The Demons and Part II: The Art, whereby the first"part consists of eight chapters following on particular examples of tortured artists and the second, being factually an addendum, features only the Tortured Artists Timeline. A Brief and Deliberately Random History of Pain, Suffering, and Artistic Triumphs.

${ }^{9}$ Valuable and substantially more complex insights, albeit from mutually different perspectives and most importantly in diverse forms, regarding the life and work of Vincent Van Gogh offer in their books Robert Wallace (The World of Van Gogh: 1853 - 1890) and Irving Stone (Lust for Life). 
${ }^{10}$ In particular C. Homburg's take on Vincent Van Gogh being, hence the subtitle of the paper, "a case in point" appears to be very complex, saturated and therefore inspirational, because the author makes the wide contexts of the tortured-artist subject-matter readily apparent.

${ }^{11}$ A deeper look - not only in terms of the nature of the discussed issues - into the series' philosophy is provided by the book with a well-chosen subtitle Bigger on the inside. See Lewis - Smithka (eds.), 2010.

${ }^{12}$ The title of one of the chapters in the book Science fiction audiences. Watching Doctor Who and Star Trek is in this connection symptomatic: 'But why is Doctor Who so attractive?' Negotiating ideology and pleasure. See Tulloch, - Jenkins, 1995, pp. 107-123.

${ }^{13}$ Regarding in particular the genesis and also the significance of the TV series Doctor Who, Nicholas J. Cull's chapter entitled Tardis at the OK corral: Doctor Who and the USA has a lot to offer. See Cook - Wright (eds.), 2006, pp. 52-70.

${ }^{14}$ Regarding Doctor Who's revival, which the episode Vincent and the Doctor is also a part of, see Hills, 2010.

${ }^{15}$ Similarly to Loving Vincent, albeit, of course, not to such an extent, while truthfully re-imagining Van Gogh's world, several of the sets where the story of the episode takes place are designed to resemble some of the artist's paintings, for example Bedroom in Arles.

\section{Acknowledgment}

The paper was written as part of two research grants: VEGA no. 1/0426/17 Iconisation of suffering and its meaning in verbal, artistic and cultural frame I (Intersemiotic, interdisciplinary and intercultural examination) and APVV17-0026 Thematological interpretation, analysis and systematization of arch-narratives as semiotic models of the life world and existential strategies.

\section{Martin Boszorád}

Institute of literary and artistic communication

Faculty of Arts, Constantine the Philosopher University in Nitra

Štefánikova 67

94974 Nitra, Slovakia

mboszorad@ukf.sk 